\title{
The Challenges for the European Tourism Sustainable
}

\section{Denada Olli}

\author{
Lecturer at 'Fan S. Noli' University, Faculty of Economy,
} Department of Marketing, Branch Korça, Albania.

\section{Doi:10.5901/mjss.2013.v4n9p464}

\begin{abstract}
The purpose of this paper is to stimulate action to make European tourism more sustainable and to maintain this as a continuous process. The concept of sustainable development has been widely accepted as the basis for planning and managing the way we live now and in the future. Sustainability is all about understanding impacts and being alert to them all the time, so that the necessary changes and improvements can be made. In this study discuss some key challenges that must be addressed if these aims are to be met. Many of the challenges identified below are relevant to more than one of the aims of sustainable tourism, with a combination of economic, social and environmental implications.A critical objective for tourism sustainability in Europe is to ensure that the destination management process fully embraces sustainability objectives and principles. This study has set out the key challenges for making European tourism more sustainable, mechanisms for tackling them and the responsibilities of the main players. It has also set out a general action framework. All organisations and stakeholders should now consider how they can best contribute to taking this forward, at all levels.
\end{abstract}

Keywords : European tourism, sustainable tourism, challenges, development.

\section{Tourism - a special relationship with sustainable development}

The concept of sustainable development has been widely accepted as the basis for planning and managing the way we live now and in the future. Sustainable development requires the safeguarding the earth's capacity to support life in all its diversity. It embraces concerns for environmental protection, social equity and the quality of life, cultural diversity and a dynamic, viable economy delivering jobs and prosperity for all.

Tourism is an activity that can have a truly major impact on sustainable development. Europeans account for over half of all international travel, and visits by Europeans provide an important source of income for many developing countries. Of equal significance for sustainable development, however, is the special relationship that tourism, compared with other economic activities, has with the environment and society. This is because of its unique dependency on quality environments, cultural distinctiveness and social interaction, security and wellbeing. On the one hand, if poorly planned or developed to excess, tourism can be a destroyer of these special qualities which are so central to sustainable development. On the other, it can be a driving force for their conservation and promotion - directly through raising awareness and income to support them, and indirectly by providing an economic justification for the provision of such support by others. Tourism can be a tool to aid or drive regeneration and economic development as well as enhancing the quality of life of visitors and host communities. Making tourism more sustainable will contribute significantly to the sustainability of European society.

The last few years have seen a considerable increase in consumer awareness of the impact of holidaymaking, partly fuelled by extensive media coverage. Tourists are clearly concerned that the destinations they visit should be attractive, with clean and well maintained environments. Nature and culture based tourism market segments have been strongly growing. A number of surveys in different European countries have revealed that when asked the majority of travellers say that, other things being equal, they would be more likely to choose enterprises that care for the environment and local community. However, the proportion of Europeans who chose a particular type of travel specifically for reasons of environmental impact is probably still low.

\section{Response to tourism sustainability so far}

Concern for the sustainability of tourism is already well established in Europe. It is a subject that has received considerable attention from the European Commission, the European Parliament, and the Economic and Social 
Committee.

Many national governments and local authorities across Europe have paid attention to sustainability issues in the development of their tourism strategies and actions. This process is likely to be further strengthened by the requirement that government strategies are subject to Strategic Environmental Assessment. Yet there is a feeling that such awareness is not necessarily translated into concrete practical actions and that some of the key challenges and opportunities presented by the sustainable development of tourism are not being met. The response of tourism businesses to sustainability has been quite variable. Some larger companies in the sector are pursuing sustainability by introducing corporate social responsibility strategies. Only a small proportion of small tourism businesses have sought to become recognised for their environmental and social policies and practices, and it appears that in most cases positive action has depended on a personal interest and commitment by the proprietor. However, there are clear signs that the level of interest and response is growing. This has been helped by the work of trade associations and by business to business contact in the supply chain. For example, some tour operators now seek specifically to source service suppliers that adhere to sustainability criteria.

\section{The aims for sustainability of Europian tourism}

These aims are treated in 3 directions :

\subsection{Economic prosperity :}

a. To ensure the long term competitiveness, viability and prosperity of tourism enterprises and destinations.

b. To provide quality employment opportunities, offering fair pay and conditions for all employees and avoiding all forms of discrimination.

\subsection{Social equity and cohesion}

a. To enhance the quality of life of local communities through tourism, and engage them in its planning and management.

b. To provide a safe, satisfying and fulfilling experience for visitors, available to all without discrimination by gender, race, religion, disability or in other ways.

\subsection{Environmental and cultural protection}

a. To minimise pollution and degradation of the global and local environment and the use of scarce resources by tourism activities.

b. To maintain and strengthen cultural richness and biodiversity and contribute to their appreciation and conservation.

The above aims should also apply to policies and actions affecting the impact of outgoing tourism from Europe and support to the industry as an international development tool.

\section{The application of sustainability principles}

There are a number of principles behind the concept of sustainable development that have a particular bearing on tourism and the approach we should take in Europe.

1. All the various impacts of tourism should be taken into account in its planning and development. Furthermore, tourism should be well balanced and integrated with a whole range of activities that affect society and the environment.

2. Planning for the long term. Sustainable development is about taking care of the needs of future generations as well as our own. Long term planning requires the ability to sustain actions over time.

3. Achieving an appropriate pace and rhythm of development. The level, pace and shape of development should reflect and respect the character, resources and needs of host communities and destinations.

4. Involving all stakeholders requires widespread and committed participation in decision making and practical implementation by all those implicated in the outcome. 
5. Policies and actions should be informed by the latest and best knowledge available. Information on tourism trends and impacts, and skills and experience, should be shared across Europe.

6. Preventative action should be taken to avoid damage to the environment or society.

7. Continuous monitoring sustainability is all about understanding impacts and being alert to them all the time, so that the necessary changes and improvements can be made.

\section{The challenges for the european tourism sustainable :}

The paper studies some key challenges that must be addressed if these aims are to be met.

Many of the challenges identified below are relevant to more than one of the aims of sustainable tourism, with a combination of economic, social and environmental implications.

Before introducing these challenges, two important prerequisites for tourism sustainability can be identified:

1. Ensuring that the right conditions for successful tourism trading are in place

2. Anticipating and keeping abreast of change

\subsection{Challenge 1: Reducing the seasonality of demand}

The concentration of tourism trips into certain periods of the year has a major effect on sustainability. Not only does it seriously reduce the viability of enterprises and their ability to offer year round employment, it can also place severe pressure on communities and natural resources at certain times while leaving surplus capacity at others.

Seasonality of demand makes it very difficult to plan and manage the provision of tourism facilities efficiently. A process of stimulating demand and use in less busy seasons, taking up existing capacity, would enable revenue from tourism to grow while putting less pressure on the environment and community than would result from a growth in peak demand.

\subsection{Challenge 2: Addressing the impact of tourism transport}

Transport has primary consequences for minimising global and local pollution but also for the economic viability of the tourism industry the quality of life of communities and fair access to tourism for all. Sustainable transport is a key challenge .

However, the tourism sector must also respond actively and responsibly to the challenge. The approach should be to seek to retain total visitor spending and economic benefit while reducing emissions resulting from this activity.

Primary emphasis should be placed on reducing the net impact on climate change from air and car travel. Important is investing in appropriate infrastructure and services using revenue from environmental taxes where appropriate and continuously improving integration between different types of transport service and ease of use by tourists.

So, should be assessed and improved by continually updating knowledge on the effect of tourism transport on emissions, and on the likely impact of different response measures on tourism performance and as well on climate change.

\subsection{Challenge 3: Improving the quality of tourism jobs}

The tourism sector offers many job opportunities to people of all ages and skills. Particularly for young people, a job in tourism often represents the first contact with working life, supplying them with interpersonal and social competencies highly needed in a customer-minded service industry. Increasingly, there is scope for tourism to add value to employment in other sectors, through multiple occupation, and to provide new opportunities for employment in fields related to the environment and heritage. In tourism, staff to provide an integral part of the customer experience, and it is the people working in the industry that can provide it with a principal source of competitive advantage. There must be something unique in the skills, know-how and behavior of those working in the industry to enable Europe to distinguish itself from other competing locations. The challenge is for tourism business, however small, to develop well designed human resources practices. The social dialogue between employers, employees and their representatives should be strengthened. Companies should engage their employees and their representatives in setting and meeting their various sustainability targets. The challenge of improving job quality in the sector, and giving it a competitive edge, also requires 
more coordinated effort to strengthen training and establish a careers structure.

\subsection{Challenge 4 : Maintaining and enhancing community prosperity and quality of life, in the face of change}

Pressures of development are impacting on society. In all cases, the challenge is to manage change in the interests of the well being of the community. As such, it has a bearing on economic aims (retaining income in the locality and strengthening quality of jobs) and environmental aims (retaining natural and cultural heritage of the destination and avoiding degradation).

Two types of change present particular challenges and opportunities for local communities at the moment. The first relates to property development, associated with tourism, altering the character of settlements. This can bring considerable economic benefits to communities, it can also result in spreading urbanization. A second type of change comes from the restructuring of local economies, resulting from a decline in traditional activities, with tourism seen as an answer to the replacement of local income and jobs. In response to both types of change, for the careful destination planning and management is required to propose a new development is in line with market trends and future demand and to maximise the proportion of income and other benefits to local communities, through strengthening local supply chains and promoting use of local produce, shops and other services by visitors.

\subsection{Challenge 5: Minimising resource use and production of waste}

This challenge relates directly with environmental protection, but also has equally strong consequences for the wellbeing of host communities It relates both to the sustainable consumption and production and to the natural resource management.

The use of water is a major issue for the sustainability of tourism. Other issues relating to efficient resource use and waste management include: Minimising energy consumption (for example in air-conditioning and heating) and encouraging the use of renewable sources and improved technology, reducing and managing litter. Much of the action required to address this challenge rests with strengthening environmental management in tourism enterprises. The future planning of tourist destinations and the design of individual facilities should meet criteria for minimising resource use and managing waste. Innovation and creative approaches to resource management should be encouraged.

\subsection{Challenge 6: Conserving and giving value to natural and cultural heritage}

The relationship between tourism and an area's natural and cultural heritage is of critical importance. Tourism can play a key role in raising awareness and generating direct and indirect support for conservation. Looked at the other way, the quality of the natural and cultural heritage is, in most areas, fundamentally important to the generation of economic prosperity through tourism, to the quality of life of local communities and to the visitor experience. Conservation and management of natural resources is a key challenge. Many policies and conventions exist at an international and European level aimed at conserving these assets and the tourism must play its part in supporting them. The presence of many types of designation, offering both protection as well as a focus of visitor interest and interpretation, is a significant strength in Europe.

\subsection{Challenge 7: Making holidays available to all}

Social inclusion and equity are important principles of sustainable development. A specific aim is to ensure that tourism experiences are available to all without discrimination. This will also bring additional economic benefits. This challenge has wider strategic implications for sustainable tourism, in that a policy of seeking to maximise revenue from the sector without increasing volume could go against social inclusion principles. However, pursuing social tourism has also been shown to assist in the objective of reducing seasonality of demand and supporting stable year-round employment, as many people who can be reached in this way, such as pensioners, are well placed to travel outside the main season. So very important is encouraging policies and actions to support social tourism at all levels.

\subsection{Challenge 8: Using tourism as a tool in global sustainable development}

It is highly appropriate that our concern about sustainable tourism in Europe should translate also to concern for the 
effect of European tourism and tourism-related policies on global sustainable development. All the aims identified for sustainable tourism should apply to tourism development and action internationally. In this case promoting equity in tourism development and travel is very important, , where by all countries have the same right to develop tourism and citizens of all countries have an equal right to travel.

\section{Recomandations}

1. To start a new impetus in the process of making European tourism more sustainable. In part this requires those involved in tourism, in the public and private sectors, to increase their own awareness of the issues and take action to address them. However, it also requires the European Commission and all member states to recorgnise more strongly the special position of tourism in delivering sustainable development and to support the sector accordingly.

2. The overarching challenge is for the tourism sector to remain competitive while also embracing sustainability, recognising that, in the long term, competitiveness depends on sustainability. Should continue to seek tourism development but, in delivering this, the consumption and production patterns of tourism may have to change. There should be an emphasis on retaining and increasing revenue from tourism, but at a lower cost to the environment and our distinctive cultures and a higher value to society.

3. The tourism businesses and tourists should be much more actively encouraged to get behind sustainability. This is partly about accepting responsibilities but also about embracing the opportunities presented. Increasingly, sustainability should be equated with quality -tourists should recognise that places that care for the environment, their employees and local communities are also more likely also to care for them. A quality environment, and a prosperous host community, are worth paying for and need to be promoted.

4. Challenges and opportunities will vary from place to place. Can be gained by sharing knowledge and experiences on the sustainable development of tourism in different parts of Europe and it sets out a framework and recommendations for moving forward together.

5. The challenge of improving job quality in the sector, and giving it a competitive edge, also requires more coordinated effort to strengthen training and establish a careers structure, throught strengthening the application of common standards in tourism training across Europe, and mutual recognition of qualifications. Exchanging good practice in tourism training across Europe, removing language and other barriers to common uptake and active promotion to stimulate response to tourism as a career and participate in training at all levels.

6. Being more prepared to use the tourism argument (as an economic driver) as a reason to fund the protection of nature and culture and prevent damaging change and strengthening the relationship between protected areas and local tourism interests, within the context of a sustainable tourism strategy and the action plan.

7. The tourism does not damage natural and cultural resources. For this is nesassary strengthening the development, interpretation and promotion of quality products and services based on natural and cultural heritage, including traditional crafts, local produce and other elements of local distinctiveness, as a component of the visitor experience. Too, developing monitoring programmes to measure trends and impacts and facilitate adaptive management.

Encouraging EU and bilateral aid programmes to recognise, and support, appropriate tourism development as a tool for sustainable development and poverty alleviation, and to work together and with international bodies on this. Too, encouraging European tour operators and investors in tourism services abroad to abide by sustainability principles and seek to benefit the environment and local communities in which they operate. 